\title{
Alpha I Antitrypsin Therapy in Patients with Alpha I Antitrypsin Deficiency: Perspectives from a Registry Study and Practical Considerations for Self-Administration During the COVID-19 Pandemic
}

\author{
Felix JF Herth (DI' \\ Robert A Sandhaus ${ }^{2}$ \\ Alice M Turner $\mathbb{D}^{3}$ \\ Maria Sucena ${ }^{4}$ \\ Tobias Welte (D) $^{5}$ \\ Timm Greulich (1D) ${ }^{6}$ \\ 'Department of Pneumology and Critical \\ Care Medicine, University of Heidelberg, \\ Heidelberg, Germany; ${ }^{2}$ Division of \\ Pulmonary, Critical Care and Sleep \\ Medicine, National Jewish Health, \\ Denver, CO, USA; ${ }^{3}$ Institute of Applied \\ Health Research, University of \\ Birmingham, Birmingham, England; \\ ${ }^{4}$ Pulmonology Department, Centro \\ Hospitalar Universitário do Porto, Porto, \\ Portugal; ${ }^{5}$ Department of Pulmonary and \\ Infectious Diseases, Hannover Medical \\ School, Hannover, Germany; \\ ${ }^{6}$ Department of Internal Medicine and \\ Pneumology, University Hospital \\ Marburg, Marburg, Germany
}

\begin{abstract}
Alpha 1 Antitrypsin deficiency (AATD) is a hereditary condition characterized by low serum Alpha 1 Antitrypsin (AAT) levels and a predisposition towards early-onset emphysema. Infusion of AAT is the only disease-modifying therapy that can sufficiently raise plasma AAT levels above the putative protective threshold and reduce the decline in lung density loss. Several randomized controlled trials (RCTs) and registry studies support the clinical efficacy of AAT therapy in slowing the progression of AATD-related emphysema and improving survival outcomes. The COVID-19 pandemic has prompted physicians to develop additional strategies for delivering AAT therapy, which are not only more convenient for the patient, but are "COVID-19 friendly", thereby reducing the risk of exposing these vulnerable patients. Intravenous (IV) self-administration of AAT therapy is likely to be beneficial in certain subgroups of patients with AATD and can remove the need for weekly hospital visits, thereby improving independence and well-being. Increasing the awareness of self-administration in AATD through the development of formal guidelines and training programs is required among both physicians and patients and will play an essential role, especially post-COVID-19, in encouraging physicians to consider self-administration for AATD in suitable patients. This review summarizes the benefits of AAT therapy on the clinical endpoints of mortality and quality of life (QoL) and discusses the benefits of self-administration therapy compared with conventional therapy administered by a healthcare professional. In addition, this review highlights the challenges of providing AAT therapy during the COVID-19 pandemic and the potential considerations for its implementation thereafter.
\end{abstract}

Keywords: Alpha 1 Antitrypsin, Alpha 1 Antitrypsin deficiency, COVID-19, efficacy, selfadministration

\section{Introduction}

The Alpha 1 Antitrypsin (AAT) protein is best known for its function as an inhibitor of the serine protease, neutrophil elastase (NE), an enzyme responsible for the proteolytic degradation of lung elastase and alveolar and interstitial lung tissue. ${ }^{1-3}$

Expression of AAT is determined by a variety of mutations in the SERPINA1 gene. In healthy individuals, the normal allele for the protease inhibitor is $P I^{*} M$, associated with the genotype $P I^{*} M M$; however, in patients with inherited AAT deficiency (AATD), abnormal alleles include $P I^{*} S$ and $P I^{*} Z$; less commonly, there is a complete absence of the gene $\left(P I^{*} N u l l\right){ }^{4}$
Correspondence: Alice M Turner Email a.m.turner@bham.ac.uk 
Healthy individuals with the normal allele $P I^{*} M$ have serum AAT levels of $20-53 \mu \mathrm{M},{ }^{5}$ while those with a $P I^{*} S Z$ genotype have only one-third of the normal AAT concentration. ${ }^{4}$ However, homozygosity for the $P I^{*} Z Z$ genotype accounts for nearly all $\left(\sim 90 \%{ }^{4}\right)$ of patients with AATD, ${ }^{4,6}$ who present with low or undetectable serum AAT levels. ${ }^{3}$

Genetic deficiency of AAT results in an imbalance in the activity between AAT and NE, where unopposed NE leads to a breakdown in lung parenchyma ${ }^{7}$ and a greater predisposition towards early-onset emphysema. ${ }^{3}$

At present, a human alpha 1 proteinase inhibitor (Respreeza ${ }^{\circledR}$, CSL Behring, GmbH, Emil-von-BehringStraße, Marburg, Germany), which targets the underlying pathophysiological mechanisms of AATD, is the only approved IV AAT therapy licensed for self-administration in Europe. ${ }^{8}$ Conclusive evidence for the clinical efficacy of AAT therapy was first demonstrated by the Randomized, Placebo-controlled Trial of Augmentation Therapy in Alpha 1 Proteinase Inhibitor Deficiency (RAPID) program, ${ }^{3,9,10}$ which highlighted the importance of early AATD detection and treatment in preserving functional lung tissue and reducing the severity and frequency of lung infections. ${ }^{11}$ The RAPID trial builds on evidence from early observational studies, the largest of which, the AATD deficiency registry study $(\mathrm{N}=1129)$ by the National Heart, Lung, and Blood Institute (NHLBI) in the US, demonstrated a treatment benefit of AAT therapy within a specific range of forced expiratory volume in 1 second $\left(\left[\mathrm{FEV}_{1}\right]\right.$, mean predicted $\left.\mathrm{FEV}_{1} 35-49 \%\right)$ in patients with a severe impairment of lung function. ${ }^{9}$ These findings reflect those published from the DanishGerman registry $(\mathrm{N}=295)$, which demonstrated the most noticeable treatment benefits in patients with a predicted $\mathrm{FEV}_{1}$ of between $31-65 \%{ }^{12}$ Recent re-analysis of 1129 patients from the NHLBI registry by Rahaghi et al demonstrated that AAT therapy significantly improved overall survival (OS) in all subjects $(\mathrm{p}<0.0001)$. In addition, OS was greater in patients receiving AAT therapy compared with never receiving AAT therapy, in all percentiles of predicted $\mathrm{FEV}_{1} \%$ from $10 \%$ to $60 \%$ ( $<<0.05$ in all deciles), demonstrating that even patients with advanced lung disease can benefit from AAT therapy. ${ }^{13}$

AAT therapy is administered as a weekly IV infusion by a healthcare professional (HCP) in an outpatient clinic or practice ${ }^{14}$ and with appropriate training, is licensed for self-administration. ${ }^{8,15}$ However, the need for weekly hospital visits may be a burden to some patients and has been made more challenging by the COVID-19 pandemic. The pandemic has challenged the effective management of patients with AATD in many countries across healthcare settings. Emerging treatment options in AATD, such as self-administration, therefore, aim to improve patient convenience alongside extending survival and reducing mortality.

Self-administration has already been implemented in other respiratory conditions, including bronchiectasis, ${ }^{16}$ asthma, ${ }^{17}$ chronic obstructive pulmonary disease (COPD $)^{18}$ and cystic fibrosis, ${ }^{19}$ and also in blood disorders such as severe hemophilia and hereditary angioedema (HAE) ${ }^{20}$ providing patients with a level of autonomy in managing their own treatment. ${ }^{14}$ However, the literature surrounding self-administration in patients with AATD is limited. Raising awareness of self-administration alongside improving patient education on the type and severity of disease, is imperative and may help physicians and patients with AATD turn to this treatment method.

This review focuses on the efficacy of AAT therapy regarding mortality and QoL in patients with AATD, and the applicability of self-administration of AAT therapy in these patients. Specific emphasis is placed on the benefits of self-administration compared with conventional HCP-administration and the challenges associated with providing AAT therapy during the COVID-19 pandemic.

\section{The Impact of AAT Therapy on Mortality and QoL Mortality}

There is an abundance of evidence derived from registry studies in support of clinical efficacy of AAT therapy for improving survival based on the physiological marker of $\mathrm{FEV}_{1} .{ }^{9}$ The largest of these observational studies, conducted in 1998, analyzed data from the NHLBI registry (US) in patients with AATD and demonstrated a lower mortality risk in patients who received IV AAT therapy $(\mathrm{n}=722)$ compared with those who received no therapy $(\mathrm{n}=326$; risk ratio $=0.64 ; 95 \%$ confidence interval [CI]: $0.43-0.94 ; p=0.02) .{ }^{9}$ In addition, the lowest mortality rates were associated with patients with an initial $\mathrm{FEV}_{1}$ within the range 35-49\% predicted $(\mathrm{n}=185$; risk ratio $=0.21 ; 95 \%$ CI: 0.09 $0.50 ; \mathrm{p}<0.001) .{ }^{9}$ Wencker et al demonstrated that the greatest treatment benefit in slowing the decline in lung function was observed in a subgroup of patients with 
a moderate impairment in lung function with an initial FEV $_{1}$ of $>60 \%$ predicted. ${ }^{21}$ However, Rahaghi et al recently demonstrated that AAT therapy significantly improved $\mathrm{OS}$ in all predicted $\mathrm{FEV}_{1} \%$ deciles from $10 \%$ to $60 \%$ compared with those who never received AAT therapy $(p<0.05)$. In addition, response to treatment in the RAPID trial did not seem to vary by starting $\mathrm{FEV}_{1}{ }^{22}$ Therefore, there is no clinical rationale to limit screening and treatment of these patients by the severity of illness as defined by $\mathrm{FEV}_{1}{ }^{13}$

Using computerized tomography densitometry, a 2-year, double-blind, randomized, placebo-controlled trial (RAPID) and its open-label extension phase (RAPID-OLE), were the first to demonstrate the disease-modifying effect of AAT therapy on emphysema progression. In RAPID-OLE, the beneficial effect of AAT therapy on the rate of lung density decline over the first 2 years was maintained after 4 years compared with patients who switched from placebo to AAT therapy $(-1.63 \mathrm{vs}-1.26 \mathrm{~g} / \mathrm{L} /$ year at total lung capacity, $\mathrm{p}=$ 0.04). ${ }^{23}$ Switching patients from placebo to AAT therapy between 24 and 48 months resulted in a reduction in the rate of lung density decline after two years $(0.52 \mathrm{~g} / \mathrm{L} /$ year, $\mathrm{p}=0.001) .{ }^{23}$ However, it is impossible to regain lung tissue once lost, demonstrating a potential benefit of early intervention with AAT therapy. ${ }^{3}$

RAPID-OLE also compared baseline lung density and its rate of decline between patients receiving AAT therapy and those not receiving therapy to generate the number of life-years gained, demonstrating an increase of $>5$ lifeyears in patients receiving AAT therapy compared with placebo. ${ }^{3,23}$ Results from both RAPID and RAPID-OLE highlight the disease-modifying effects of AAT therapy in AATD, for which early diagnosis and implementation of treatment is able to slow the progression of AATD-related emphysema and lung density loss, potentially resulting in improved mortality compared with no therapy.

\section{QoL}

Exacerbation frequency and severity are important patientreported outcomes that can negatively impact patient QoL. The St George's Respiratory Questionnaire (SGRQ) assesses a patient's symptoms, daily activity, and psychological impacts of disease. ${ }^{24}$ Stockley et al utilized the SGRQ in patients recruited to the UK-AATD database $(\mathrm{N}=454)$ to determine how the natural decline in lung function affected health status over 4 years. ${ }^{25}$ Although results demonstrated a slow deterioration in SGRQ consistent with the decline in CT lung density, indicative of disease progression, the SGRQ was highly variable and would lack sufficient power to demonstrate effects of AAT therapy on QoL. ${ }^{25}$ Consequently, it is perhaps unsurprising that the effect of AAT therapy on QoL has not been confirmed in RCTs.

More recently, an observational study used retrospective national registry data to investigate health outcomes in patients $(n=1312)$ receiving AAT therapy compared with standard care. ${ }^{26}$ While the full study results have not yet been published, greater 10-year OS in patients using AAT therapy $(80.0 \%)$ compared with a matched group $(68.5 \% ; \mathrm{p}<0.001)$ has been demonstrated. ${ }^{26}$ Benefits on QoL deterioration were also seen. ${ }^{27}$ There is likely to be a heavy reliance on patient registries to support the clinical efficacy of AAT therapy on health-related outcomes in the future.

\section{Administration of AAT Therapy in Patients with AATD Conventional HCP-Administered Therapy}

The provision of AAT therapy across Europe is variable, with some countries having no access at all. ${ }^{14}$ In countries where AAT therapy is available, AAT has traditionally been administered by an HCP in a healthcare center or clinic. The need for weekly visits to hospital can impact QoL by reducing autonomy and prove inconvenient for many patients, especially for those in full-time employment.

Treatment can therefore be delayed or even missed, especially in patients with a substantial journey time. In patients with advanced lung disease, under exacerbating conditions, attending a clinic poses a physical challenge. ${ }^{28}$

HCP-administered therapy performed by a visiting nurse has also been carried out in a home setting and has been demonstrated to improve convenience for patients compared with hospital-based therapy. ${ }^{29}$ A recent study of 16 patients by Annunziata et al reported similar findings with regard to convenience: the study demonstrated that 3 months of homebased AAT therapy led to significant QoL benefits vs baseline $(\mathrm{p}<0.01)$, including less stress, less burden on family and friends, and less interference with daily life compared with hospital administration, with no reported adverse events (AEs). ${ }^{30}$ Moreover, adherence to home-based AAT therapy was $100 \%$ and no patients discontinued treatment. ${ }^{30}$

\section{Self-Administration of AAT Therapy}

The self-administration of medicines, defined as administration performed by a non-professional, patient, spouse or 
partner, ${ }^{14}$ has successfully been carried out in patients with a variety of diseases, such as $\mathrm{HAE}^{31,32}$ and hemophilia, ${ }^{20}$ and for the self-infusion of antibiotics. ${ }^{33}$

Compared with conventional HCP administration, selfadministration enables patients to manage their disease in their own environment, reducing time off work, hospital visits, travel and the risk of contracting SARS-CoV-2 and/ or other airborne viruses. ${ }^{34}$

This alternative treatment practice has been shown to be well tolerated, can improve QoL ${ }^{34-36}$ and enables patients to become experts in their own disease management. ${ }^{14,31,35}$

\section{Real-World Evidence: Patient and Physician Experience with Self-Administration in AATD}

To demonstrate the applicability of self-administration of IV AAT therapy to the real world, we report a clinical case study of a 52-year-old female patient diagnosed with bronchiectasis and severe AATD ( $P I^{*} Z Z$ genotype) who has successfully selfadministered AAT therapy for 3 years (see Table 1 for information). This patient case demonstrates the clinical benefits of self-administration on reducing exacerbation frequency and improving QoL compared with receiving no AAT therapy (Table 1). The patient received self-administration training before beginning treatment in 2017 and reported independence and adequate online training support as the most important benefits for self-administration therapy.

Evidence highlighting the practicalities and satisfaction of self-administering AAT therapy in patients with AATD has so far only been captured by one cross-sectional patient satisfaction survey conducted by the AlphaNet Disease Management and Prevention Program (US). ${ }^{37}$ A majority of the 555 patients with AATD surveyed, had never selfadministered their AAT therapy $(504 / 555,90.8 \%)$ and were not considering this strategy due to a lack in confidence (135/ $555,26.2 \%$ ) or were happy with their current treatment regimen $(442 / 555,79.7 \%)$. Forty-four patients (44/555, 7.9\%) self-administered their AAT therapy; all were either "very satisfied" (42/44, 95.0\%) or "satisfied" (2/44, 5.0\%) with their treatment. ${ }^{37}$ Few AEs related to self-administration were reported. $^{37}$ The majority of patients who selfadministered their AAT therapy (41/44, 93.0\%) reported independence as the most important advantage to selfadministering their treatment. ${ }^{37}$ In addition, in many patients who chose to self-administer, their primary source of information was from other patients $(17 / 44,39.5 \%)$, rather than their physician $(11 / 44,25.9 \%),{ }^{37}$ which indicates the need for educational training programs to raise awareness of the possibilities of self-administration as a treatment means in AATD in both patients and clinicians.

\section{Practical Considerations with Self-Administration Therapy Challenges with Self-Administration Therapy}

Potential concerns over introducing self-administration in AATD can be drawn from clinical experience in HAE and hemophilia, where self-administration is common practice. Physicians may be cautious due to a potential lack of resources at home compared with a hospital setting. Further concerns from patients include difficulties with administration technique for both IV and subcutaneous infusion, ${ }^{34}$ and the confidence and ability to self-administer independently. ${ }^{37}$ One study of self-administration in patients with AATD reported issues relating to treatment infusion, including difficulties locating veins and selecting infusion sites, intravenous stick injuries, occlusion of ports with scar tissue, and problems switching from vein to port. ${ }^{37}$ Moreover, particular attention should be paid to potential hypersensitivity reactions (eg, anaphylaxis) when self-administering AAT therapy. ${ }^{8}$ Other possible complications associated with selfadministration and/or AAT therapy include infusion site reactions (such as itching ${ }^{30,38}$ ), infections, ${ }^{39,40}$ lineassociated sepsis, ${ }^{41}$ volume overload, fever, flu-like symptoms, nausea and dyspnea, among other AEs. ${ }^{30,42}$ Severe AEs associated with AAT therapy, including anaphylaxis and congestive heart failure, have been reported in a handful of patients with AATD. ${ }^{42}$ It is important for both HCPs and patients to be aware of and prepared for potential AEs, should they occur outside of a healthcare setting, before opting for self-administration of AAT therapy.

Despite these potential issues, in a recent survey of 15 clinicians treating AATD across 13 European countries, all respondents reported that they would consider selfadministration of AAT therapy in patients for whom it was deemed appropriate. Further, 100\% of clinicians stated that they would consider switching patients from hospitalbased or home-based AAT therapy to self-administration if these patients had the potential to benefit the most from this treatment strategy. ${ }^{14}$

\section{Appropriate Patient Selection}

The authors of this paper consider that self-administration is likely to be beneficial for $30-50 \%$ of patients with 
Table I Case Study of a Patient Diagnosed with Bronchiectasis and AATD with Frequent Exacerbations, Who Has Been Self-Administering AAT Therapy for Over 3 Years

\begin{tabular}{|c|c|}
\hline \multicolumn{2}{|l|}{ Patient details } \\
\hline Gender & Female \\
\hline Age, years & 52 \\
\hline Height, cm & 164 \\
\hline Weight, kg & 56 \\
\hline \multicolumn{2}{|l|}{ Clinical presentation } \\
\hline Lung infection frequency & $\begin{array}{l}\text { Recurrent infections and pneumonia } \\
3-4 \text { per year } \\
\text { No other illnesses }\end{array}$ \\
\hline Physical examination & $\begin{array}{l}\text { Left lung is weak and has always been weak } \\
\text { Coarse crackle, left more than right } \\
\text { Sputum microbiology: sometimes pneumococci, sometimes haemophilus }\end{array}$ \\
\hline Serum AAT, g/L & 0.3 \\
\hline AAT genotype & $P I * Z Z$ \\
\hline \multicolumn{2}{|l|}{ Details of treatment } \\
\hline $\begin{array}{l}\text { Year that self-administration of } \\
\text { AAT started }\end{array}$ & 2017 \\
\hline Medication & Human alpha I proteinase inhibitor (Respreeza [CSL Behring, GmbH, Emil-von-Behring-Straße, Marburg, Germany]) \\
\hline Dose & $4-5$ g per vial $(60 \mathrm{mg} / \mathrm{kg})$ \\
\hline Schedule & Weekly \\
\hline Patient training and feedback & Patient received training prior to beginning self-administration \\
\hline Patient-reported benefits & $\begin{array}{l}\text { - Reduction in exacerbation frequency with AAT therapy from } 2017 \text { to } 2019 \\
\text { - Improved QoL and independence compared with HCP-administered therapy } \\
\text { - Online support for self-administration } \\
\text { - Improved awareness of AATD and the associated benefits of self-administration among family members } \\
\text { compared with HCP-administered therapy } \\
\text { - Reduction in time spent receiving treatment and travelling to treatment centers compared with hospital- } \\
\text { administered AAT therapy } \\
\text { - Logistical flexibility - self-administration can be carried out as and where required by the patient }\end{array}$ \\
\hline Patient-reported challenges & None \\
\hline
\end{tabular}

Abbreviations: AAT, Alpha I Antitrypsin; AATD, Alpha I Antitrypsin deficiency; HCP, healthcare professional; QoL, quality of life.

AATD and, with appropriate training, can be learned and performed proficiently at home. However, careful selection of patients is important for the success of this approach, with selection based on psychological, logistical and physiological parameters (Figure 1); the treating physician, nurse, and patient should all be in agreement before beginning AAT therapy. ${ }^{14}$

Based on clinical experience in a variety of blood disorders and in AATD, specialists have outlined the qualities of the most suitable patients for self-administration, which include: a willingness to learn, confidence to selfadminister, and adequate cognitive function. ${ }^{14,28,43}$ In addition, patients who have logistical difficulties with attending hospital, including limited access to the hospital, or a long journey time, and those in full-time employment or who are caregivers themselves, ${ }^{14}$ should be considered.

The skills required for IV self-administration of AAT therapy can be drawn from UK guidelines for the selfinfusion of IV antibiotics (Table 2) ${ }^{44}$ and recommendations for the delivery of insulin in patients with Diabetes 


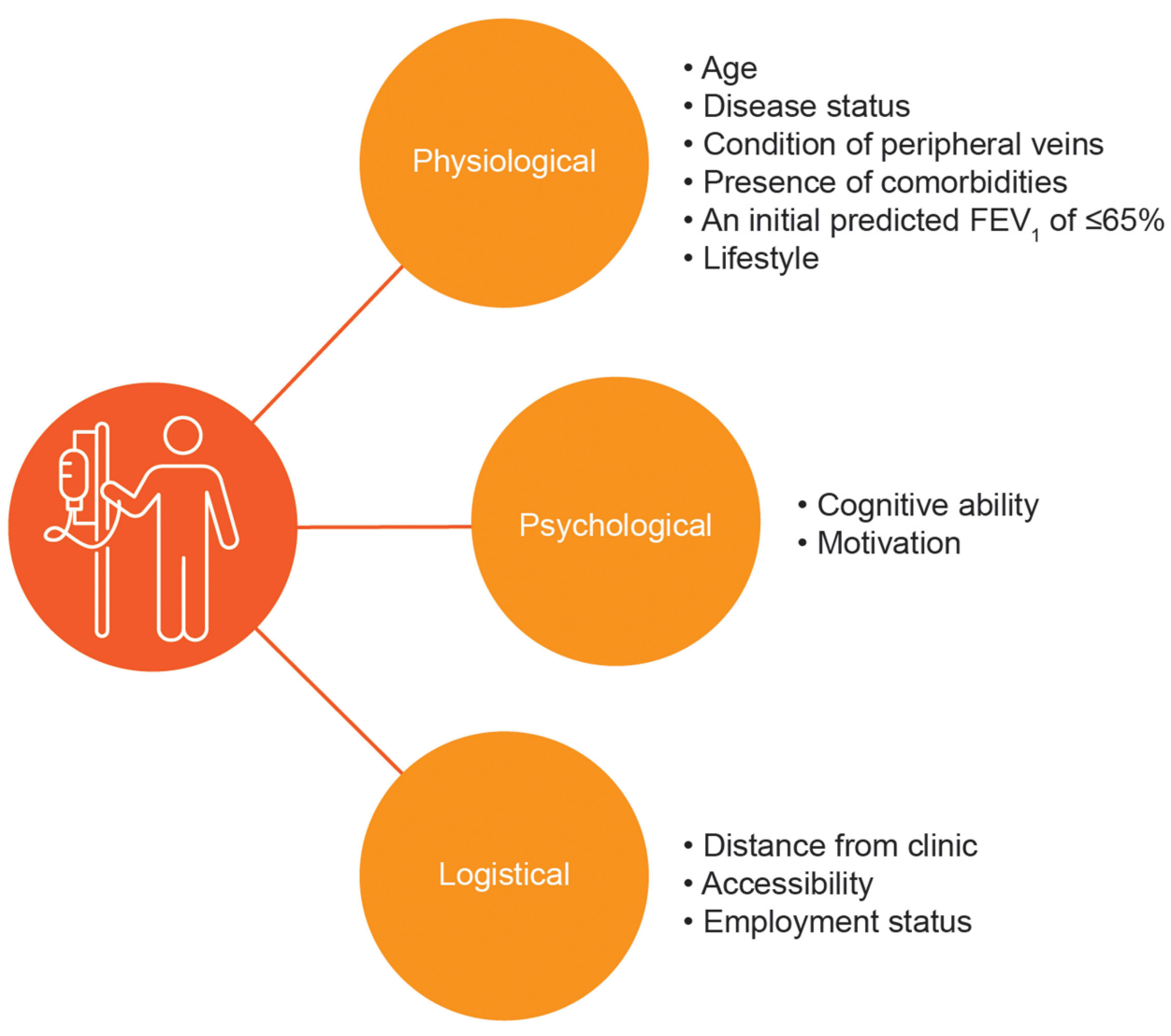

Figure I Factors considered when selecting appropriate patients with AATD to begin on self-administration therapy. Abbreviation: $\mathrm{FEV}_{\mathrm{l}}$, forced expiratory volume in I second.

Mellitus. Both UK and global guidelines for the reconstitution and administration of insulin ${ }^{45,46}$ state that patients who self-administer require good eyesight, ${ }^{45}$ no sign of tremors ${ }^{46}$ and manual dexterity. ${ }^{43,45}$ Any physical issues preventing local venous access such as the condition of peripheral veins should also be considered.

A patient's age and disease history should also be considered: benefits have been observed in patients receiving AAT therapy who were $<50$ years of age, ${ }^{14}$ with no comorbidities ${ }^{14}$ and who were symptomatic with an initial predicted $\mathrm{FEV}_{1}$ of $\leq 65 \%$. ${ }^{47,48}$

Table 2 Five Competencies Patients are Required to Demonstrate Before Beginning Therapy

\begin{tabular}{|l|l|}
\hline & Competency Skill \\
\hline 1 & Hygiene and infection control \\
2 & Drug reconstitution and administration \\
3 & IV access management and maintenance \\
4 & Safe storage of IV therapy kit \\
5 & Correct disposal of sharps \\
\hline
\end{tabular}

Note: Data from West Suffolk NHS Foundation Trust Policy. ${ }^{44}$ Abbreviation: IV, intravenous.
It is also strongly advised that should the patient not wish to self-administer or not possess adequate skills to do so, considerations should be made for a partner or relative to be trained to administer for the patient. ${ }^{14}$

It should also be noted that there are limited data on the use and safety of AAT therapy in certain patient populations, including pregnant women. ${ }^{8,49-52}$ Therefore, initiation of AAT therapy (and self-administration thereof) in these individuals requires careful consideration and discussion with the patient. ${ }^{49}$

\section{Training Programs}

Self-administration of AAT therapy can only be performed in Europe following sufficient IV infusion training. ${ }^{8}$ Although at present there are no approved national training programs in AATD to support patients using selfadministration of IV AAT therapy, ${ }^{28}$ there is support among clinicians for its use in the right patient. ${ }^{14}$ Adequate selfinfusion training will be essential in patients who lack confidence and are hesitant to switch to this treatment strategy.

In the US, a majority of self-administration training for AAT therapy has reportedly been conducted by home nursing 
Table 3 The Teaching of Self-Administration IV AAT Therapy to Patients and/or a Spouse or Relative, Should Focus on a Variety of Aspects Covering Pre-, During and Post-Administrative Care

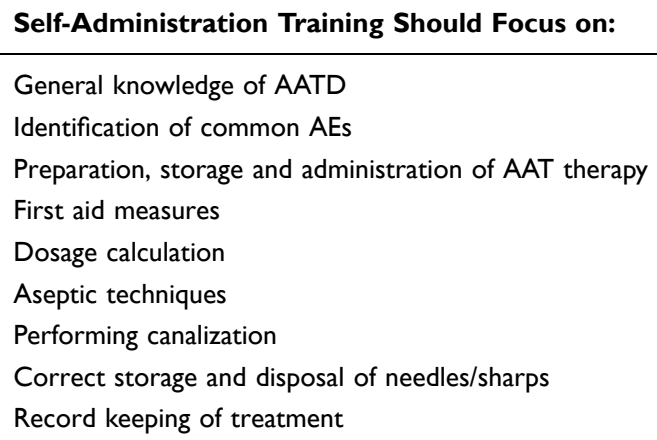

Abbreviations: AE, adverse event; AAT, Alpha I Antitrypsin; AATD, Alpha I Antitrypsin deficiency; IV, intravenous.

agencies over an average of two or three sessions. ${ }^{37}$ This is similar to the number of sessions required when learning self-administration in HAE and hemophilia, ${ }^{31,34,53}$ with some patients becoming proficient in as little as 2 hours, ${ }^{31}$ indicating the features of self-administration and aftercare ${ }^{31}$ (Table 3) can be learned quickly and easily at home. Once learned, patients tend to retain the skills for IV self- administration, as they ultimately become experts in their own disease management. ${ }^{20,28,34}$

In patients with $\mathrm{HAE}$, self-administration sessions may be facilitated by a visiting HCP in some European countries such as the UK and Germany, or by homecare agencies in the US. ${ }^{31}$ There is potential for this approach to be taken in AATD. Self-administration training conducted by the local community has also been recommended in Europe to help improve patient management and reduce healthcare costs. ${ }^{31}$

Irrespective of the training provider, patients, and if applicable a relative or partner, are initially taught how to reconstitute the drug and are subsequently taken through the practical steps for self-administration, including the choice of injection site, finding a port or vein, types of IV access and how to self-infuse ${ }^{44}$ (Figure 2).

Follow-up sessions are recommended at regular intervals to ensure the retention of infusion skills and knowledge about their condition and potential AEs. Examples from guidelines for the management of hemophilia state that teaching programs should include the monitoring of health status and associated outcomes, including how to
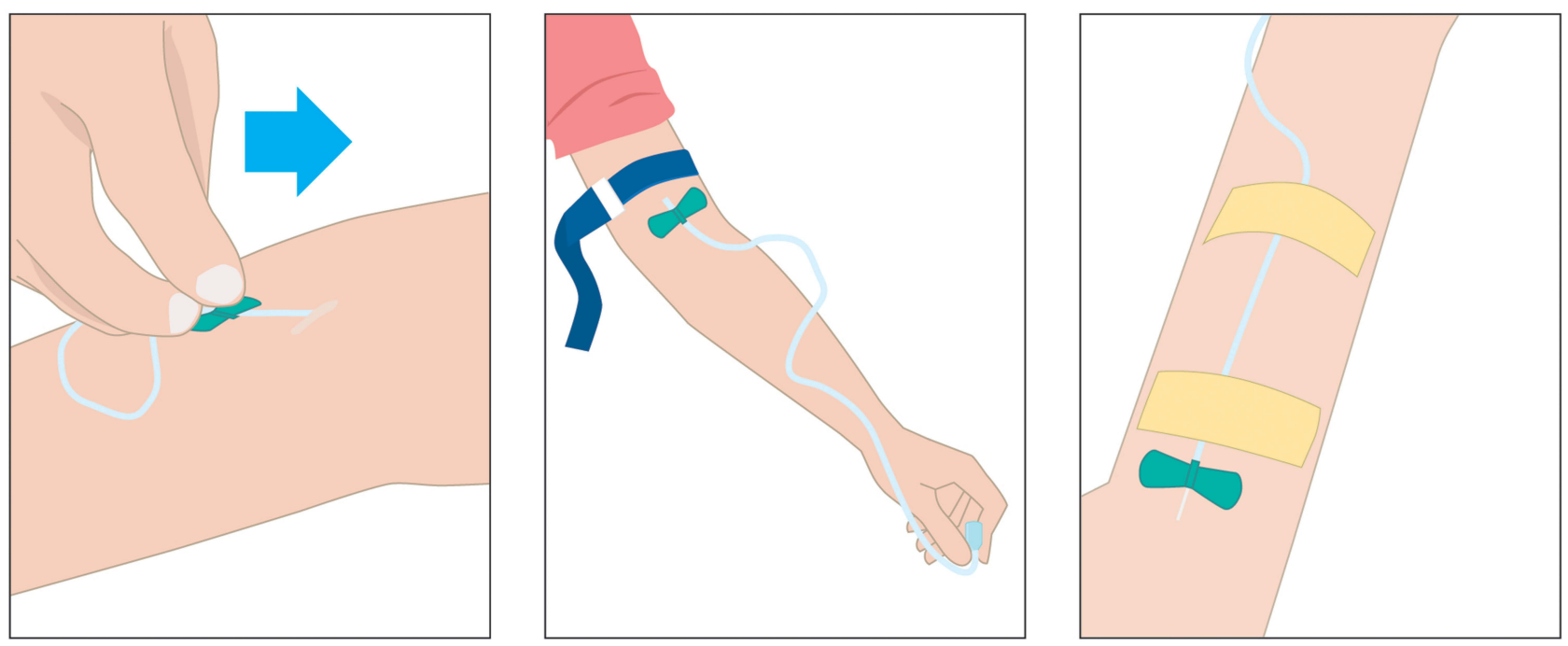

Key points for administration
- Work under aseptic conditions
- Reconstitute the concentrate
- Fill the syringe for infusion
- Infuse the drug appropriately
- Take care of the injection site and veins
- Document the infusion

Figure 2 Practical aspects taught to patients for self-administering AAT therapy. Abbreviation: AAT, Alpha I Antitrypsin. 
recognize AEs through keeping a record or log of treatment and symptoms. ${ }^{54}$

Proficiency of self-administration skills is developed through experience and individual learning; however, facilitating individualized self-administration training during the COVID-19 pandemic is a challenge, given that many patients may not feel comfortable with closecontact teaching. HCPs who provide self-administration training may wish to consider alternative approaches such as remote or online learning, in addition to the provision of resources such as patient handbooks, training manuals and check sheets, or access to a 24-hour patient helpline. ${ }^{31}$ The additional costs of training programs, patient resources and follow-up sessions should not be a reason to disregard this treatment means, ${ }^{14}$ given that cost savings may accrue from reduced staff time at infusion visits.

\section{Regulatory Aspects of Self-Administration}

Self-administration of AAT therapy is approved in Europe when recommended by a physician. ${ }^{8}$ Examples of the legislation regarding self-administration can be taken from hemophilia care, where documentation is required to confirm both the applicability of the patient for selfadministration and thereafter, the completion of appropriate training. ${ }^{31} \mathrm{HCPs}$ are required to schedule education and training sessions with the patient and advise on the number of training sessions required to reach a satisfactory competency standard. ${ }^{55}$ They are also required to inform the patients of possible AEs (delayed and late AEs), what to do in case of an $\mathrm{AE}$ and provide an emergency contact for advice. ${ }^{44}$

It is essential that a patient's legal responsibilities, including accountability for their own self-administration practice once they have received the appropriate training ${ }^{44}$ and self-reporting of any AEs/serious AEs, are made clear. ${ }^{56}$ If patients experience an $\mathrm{AE}$, they should firstly seek advice from an HCP. The European Medicines Agency states that patients can report AEs directly through online patient reporting forms hosted by national medicines regulatory authorities or by email or telephone; in doing so, they are required to provide specific treatment information $^{57}$ (Table 4). Clinicians are also expected to provide similar patient information when reporting any suspected AEs directly to their national authority (Table 4).
Table 4 Information Required by Patients and Clinicians When Submitting an Online AE Report to a Local Authority

\begin{tabular}{|l|l|}
\hline AE Reported by a Patient & AE Reported by a Clinician \\
\hline - Age and sex of patient & - Age and sex of patient \\
- Description of the side effects & - Whether the infection was diagnosed \\
- Name of medicine (brand name & through testing or based on clinical \\
and active ingredient) & symptoms alone \\
- Medicine batch number & - Description of the side effects \\
- Whether the patient was taking & - Name of medicine (brand name and \\
any other medicines at the time & active ingredient) \\
- Any other health conditions & - Dose and duration of treatment with \\
& relevant medicine \\
& - Medicine batch number \\
& - Any other medicines taken at the time \\
& of AE, including non-prescription \\
& medicines or contraceptives \\
& - Any other health conditions
\end{tabular}

Note: Data from European Medicines Agency. ${ }^{57}$

Abbreviation: $\mathrm{AE}$, adverse event.

The development of formal regulatory guidelines for the self-administration of IV AAT therapy is required to establish a consensus that HCPs can refer to on a global scale.

\section{Self-Administration of AAT Therapy During the COVID-I 9 Pandemic}

The risk of severe outcomes from COVID-19 in patients with AATD receiving hospital treatment

Patients with AATD with a homozygous $P I^{*} Z Z$ genotype have an increased risk of developing early onset emphysema, ${ }^{58,59}$ chronic liver disease, ${ }^{60}$ bacterial exacerbations and a prolonged course of infection. ${ }^{61}$ It is therefore vital that once patients have started treatment with IV AAT therapy, treatment regimens remain consistent, and there is some evidence that interruption of infusion may lead to poor health outcomes.

The consequences of withdrawing IV AAT therapy after a prolonged period was evidenced in 19 patients with AATDassociated emphysema ( $\mathrm{FEV}_{1} \sim 40 \%$ of predicted value) from the RAPID-OLE extension trial, due to removal of reimbursement for IV AAT therapy by the Irish healthcare authorities. ${ }^{59}$

Interruption of treatment after 9 years was associated with a reduction in circulating AAT levels and antielastase capacity, and an increase in respiratory exacerbations, compared with the same period in the previous year $(1.5 \pm 0.2$ per patient vs $0.5 \pm 0.1$ per patient, respectively, $\mathrm{p}=0.002)$. This was matched by an increase in circulating levels of several pro-inflammatory cytokines including interleukin (IL)-1 $\beta$, IL-6, IL-8 and soluble tumor necrosis 
receptor 1. Increases in the number of hospitalizations compared with the same period in the previous year were also observed $(p=0.003)$. After withdrawal of AAT therapy for only $77 \pm 2$ days, 2 of the 19 patients had died from respiratory failure. ${ }^{59}$

Owing to pre-existing impaired lung function and/or emphysema associated with AATD, ${ }^{58}$ COVID-19 poses a potential risk for developing severe complications in patients with AATD ${ }^{62}$ The potential mechanisms underlying the increased susceptibility of these patients to COVID-19 has recently been described. ${ }^{62,63}$ Firstly, AAT may prevent SARS-CoV-2 infection by blocking the activity of Transmembrane Serine Protease 2 (TMPRSS2), ${ }^{63,64}$ a cell membrane-bound protease that facilitates virus entry into host cells. However, it has been suggested that the lack of AAT in patients with AATD may activate TMPRSS2, therefore facilitating SARS-CoV-2 uptake. ${ }^{62}$ Secondly, circulating AAT has known inhibitory effects on thrombin and plasmin; ${ }^{63}$ as such, AATD may also be associated with an increased risk of coagulation disorders ${ }^{65}$ with hyper coagulopathy linked to severe COVID-19 symptoms. ${ }^{66}$ Finally, there is evidence to suggest that in patients infected with SARS-CoV-2, higher ratios of IL-6:AAT are predictors of long intensive care stays compared with lower ratios of IL-6: AAT, which are associated with shorter stays in intensive care and quicker clinical resolution. ${ }^{62,67}$

The identification of potential mechanisms underlying the increased susceptibility of patients with AATD to COVID-19 has led to a number of calls to action for the management of patients with AATD. ${ }^{62}$ These actions include; firstly, the call for screening of patients recovering from COVID-19 for AATD; secondly, the recommendation by public health services to screen SERPINA1 genotypes in patients at high-risk of AATD and concurrently test for COVID-19, to establish if there is an association between different SERPINA1 genotypes and incidence of SARS-CoV-2 infection; thirdly, plasma AAT concentrations should be measured for patients with AATD and their immediate family, if diagnosed with COVID-19, due to the higher risk of infection by SARS-CoV-2 and the potential worsening symptoms; finally, if a patient receiving AAT therapy becomes unwell and is admitted to hospital, standard-dose infusions should be continued as normal, although higher doses should also be considered. ${ }^{62}$

These call to actions for patients with AATD may help to reduce mortality and morbidity associated with COVID19. Further data assessing the relationship between AATD and COVID-19 are currently being collected by the
European Alpha 1 Research Collaboration (EARCO) and are due to be published in 2021. EARCO is a clinical research collaboration of the European Respiratory Society that aims to drive the collaboration of specialist AATD clinicians and researchers to guide research priorities and collect prospective, standardized, longitudinal real-world data, to ultimately advance understanding of the disease and improve patient care. ${ }^{28,68}$

AlphaNet, a non-profit organization in the US, which provides patient support through the Alpha 1 Disease Management and Prevention Program ${ }^{69}$ is also investigating the impact of COVID-19 on treatment modalities in AATD. Evidence from recent observational data demonstrate that COPD is a risk factor for poor clinical outcomes in patients who contract COVID- $19,{ }^{70}$ with a greater disease severity and higher risk of mortality in patients with COPD compared with individuals without COPD.$^{71}$ It can be assumed that the same is true for patients with emphysema caused by AATD.

To ensure continuation of treatment and reduce the exposure of these patients to respiratory viruses, selfadministration of AAT therapy should be encouraged in as many existing and newly diagnosed patients as possible who meet the eligibility criteria, as well as moving patients from existing AAT therapy regimens to selfadministration. Moreover, there is evidence that AAT may reduce the severity of COVID-19 by antagonizing some of the pathogenic mechanisms of SARS-CoV-2. ${ }^{63}$ In a recent publication by Bai et al, it was postulated that AAT may have inhibitory effects on TMPRSS2, thrombin and plasmin, in addition to its ability to protect against RNA viruses (HIV and influenza) ${ }^{63}$ Bai et al also hypothesized that AAT may possess anti-inflammatory properties, in part through inhibiting nuclear factor-kappa B activation and ADAM17, ${ }^{63}$ which may reduce the inflammatory response to SARS-CoV-2. ${ }^{63}$ However, further studies are required to confirm the therapeutic potential of AAT therapy in patients with COVID-19, with a number of clinical trials currently ongoing (Table 5).

\section{Challenges to the Management of AATD During the COVID-19 Pandemic}

The presence of the COVID-19 pandemic has made treating patients with AATD increasingly difficult and continues to challenge the management approach of AATD in many European countries. Conventional HCP-administered AAT therapy is performed in healthcare centers and attending 
Table 5 Studies of AAT Therapy in Patients with COVID-19*

\begin{tabular}{|c|c|c|c|c|c|}
\hline Study & Study Identifier & Phase & Interventions & Key Findings & $\begin{array}{l}\text { Estimated } \\
\text { Study } \\
\text { Completion } \\
\text { Date }\end{array}$ \\
\hline \multicolumn{6}{|l|}{ A) Completed studies } \\
\hline $\begin{array}{l}\text { Individual Treatment of COVID- } \\
19 \text { by Application of Alpha- } \\
\text { I-antitrypsin }\end{array}$ & $\begin{array}{l}\text { CORSAAR-AAT } \\
\text { (NCT04799873; } \\
\text { ClinicalTrials.gov) }\end{array}$ & Observational $(\mathrm{N}=9)$ & $\begin{array}{l}\text { - Inhaled AAT therapy } \\
\text { - Combined inhaled/ } \\
\text { IV AAT therapy } \\
\text { - Remdesivir } \\
\text { - Dexamethasone }\end{array}$ & $\begin{array}{l}\text { Compared with } \\
\text { baseline, treatment } \\
\text { with AAT therapy } \\
\text { resulted in: } \\
\text { - An overall } \\
\text { improvement in } \\
\text { respiratory } \\
\text { status (per } \\
\text { WHO severity } \\
\text { class) in all } \\
\text { patients } \\
\text { - A reduction in } \\
\text { serum CRP } \\
\text { concentrations, } \\
\text { with fluctuations } \\
\text { in individual } \\
\text { patients } \\
\text { - A decrease in } \\
\text { viral load in all } \\
\text { patients }\end{array}$ & December 2020 \\
\hline \multicolumn{6}{|l|}{ B) Ongoing studies } \\
\hline $\begin{array}{l}\text { Trial of Alpha One Antitrypsin } \\
\text { Inhalation in Treating Patient With } \\
\text { Severe Acute Respiratory } \\
\text { Syndrome Coronavirus } 2 \text { (SARS- } \\
\text { CoV-2) }\end{array}$ & $\begin{array}{l}\text { NCT04385836 } \\
\text { (ClinicalTrials.gov) }^{75}\end{array}$ & Phase I $(N=150)$ & $\begin{array}{l}\text { - Inhaled AAT therapy } \\
\text { via nebulizer } \\
\text { - Placebo via } \\
\text { nebulizer }\end{array}$ & September 2020 & \\
\hline $\begin{array}{l}\text { A randomized double-blind } \\
\text { placebo-controlled, pilot trial of } \\
\text { intravenous plasma-purified alpha- } \\
\text { I antitrypsin for severe COVID- } \\
\text { I } 9 \text { illness }\end{array}$ & $\begin{array}{l}2020-001391-15 \\
(\text { EudraCT) }\end{array}$ & Phase $2(N=36)$ & $\begin{array}{l}\text { - IV AAT therapy } \\
\text { - Placebo }\end{array}$ & April 2021 & \\
\hline $\begin{array}{l}\text { A Multicenter, Randomized, } \\
\text { Open-label, Parallel Group Pilot } \\
\text { Study to Evaluate the Safety and } \\
\text { Efficacy of Prolastin Plus Standard } \\
\text { Medical Treatment (SMT) Versus } \\
\text { SMT Alone in Hospitalized } \\
\text { Subjects With COVID-19 }\end{array}$ & $\begin{array}{l}\text { NCT04495I0I } \\
\text { (ClinicalTrials.gov) }^{77}\end{array}$ & Phase $2(N=100)$ & $\begin{array}{l}\text { - IV AAT therapy + } \\
\text { SMT } \\
\text { - SMT }\end{array}$ & June 2021 & \\
\hline $\begin{array}{l}\text { Study to Evaluate the Safety and } \\
\text { Efficacy of Liquid Alphal- } \\
\text { Proteinase Inhibitor (Human) in } \\
\text { Hospitalized Participants With } \\
\text { Coronavirus Disease (COVID-19) }\end{array}$ & $\begin{array}{l}\text { NCT04547I } 40 \\
\text { (ClinicalTrials. } \\
\text { gov })^{78}\end{array}$ & Phase $2(N=100)$ & $\begin{array}{l}\text { - IV AAT therapy + } \\
\text { SMT } \\
\text { - Placebo + SMT }\end{array}$ & February 2022 & \\
\hline
\end{tabular}

Note: *Information correct as of August 2021.

Abbreviations: AAT, Alpha I Antitrypsin; CRP, C-reactive protein; IV, intravenous; SMT, standard medical treatment; WHO, World Health Organization. 
appointments may increase the risk of contracting respiratory infections. Many patients have been unwilling to attend appointments in healthcare centers because of anxiety over infection risk. The pandemic has also restricted the resources available for other diseases in treatment centers. These challenges have presented an opportunity to develop new cost-effective strategies that deliver continual, uninterrupted treatment, reducing the risk to the patient of exposure to SARS-CoV-2 and other respiratory viruses. Patients for whom self-administration therapy is deemed appropriate are likely to benefit from this treatment. ${ }^{59}$

\section{Future Perspectives in AATD}

Despite the growing evidence demonstrating the clinical efficacy of AAT therapy, access to AAT therapy in patients with AATD is not uniform, with only some European countries granting reimbursement for diagnosed patients. ${ }^{14}$

Improving the convenience of AAT therapy remains a major challenge in patients with AATD; in light of the global COVID-19 pandemic, there is an even greater demand to adopt a more convenient patient- and COVID-19-friendly treatment strategy that also minimizes patient contact and reduces virus transmission.

As new evidence emerges, it will be interesting to understand whether alterations to self-administration infusion schedules during the COVID-19 pandemic, such as that evidenced in Spain, allowing self-administration every 3-4 weeks at larger doses, are permanently adopted postpandemic. Alternative dosing strategies such as bi-weekly infusion of AAT therapy have been trialed ${ }^{10,72}$ and offer favorable pharmacokinetic and tolerability profiles. ${ }^{10,73}$

Certainly, as future data concerning dose optimization and dosage interval become available, the possibility of implementing extended-interval dosages of AAT therapy may enhance the attractiveness of self-administration therapy in patients with AATD in the years to come.

Once further data are available, the aim should be to improve the awareness of self-administration among clinicians and patients to support access to treatment, especially because not all patients are choosing self-administration, even when they are offered it. ${ }^{37}$ Understanding and addressing patient hesitancy in choosing self-administration is therefore a key research priority. The implementation of formal educational training programs will raise awareness of self-administration among clinicians and the AATD community and will likely improve its adoption. Moreover, the apparent disconnect between physician preference for selfadministration and patient hesitancy may be overcome through training, especially in patients who lack selfconfidence to administer. In addition, the provision of virtual training programs will help to support patients throughout their treatment; however, facilitating such packages especially during the present COVID-19 pandemic is likely to be difficult and will increase the demand on nursing staff, who play an important role in facilitating self-administration training. Evidence from HAE and hemophilia care demonstrates that, where there is limited available training on selfadministration, nurses and patients can attend hemophilia clinics to support the learning of administration techniques. ${ }^{31}$ In addition, nurses are encouraged to share their practice experiences, especially within smaller community clinics. Indeed, experience ensures confidence in delivering self-administration training. ${ }^{31}$ Further support for patients delivered through resources such as online learning platforms, patient resource booklets and a 24-hour helpline ensuring a point of contact in the event of an emergency, will be crucial, particularly during the COVID-19 pandemic, where regular nurse contact is unavailable.

For all its proposed benefits, self-administration may, by its very nature, be challenged by social factors. For many patients, especially the elderly, home visits by an HCP or attending hospital appointments provide a form of social interaction. Removing this option may increase feelings of loneliness and anxiety. One potential consideration could be to facilitate online patient forums or weekly video calls to provide social interaction for these patients, which may also stimulate further discussion about how AATD is managed and challenged in each patient. Nonetheless, selection of the most appropriate patients must also take these factors into consideration.

\section{Conclusions}

The RAPID and RAPID-OLE trials provided compelling evidence for the efficacy of AAT therapy in slowing the progression of emphysema in patients with AATD, and highlight the importance of early detection and treatment to preserve functional lung tissue. ${ }^{3,10}$ The COVID-19 pandemic has provided the opportunity to develop new strategies for the administration of AAT therapy that are not only more convenient for the patient, but also offer a safer alternative treatment means with the potential to improve health outcomes. Self-administration of AAT therapy is a licensed but underutilized approach that can be learned quickly with adequate training, allowing patients to become proficient in their own disease management, providing greater independence and QoL. Increasing the awareness of IV AAT therapy 
in AATD among both physicians and patients is crucial and may help patients to overcome initial fears towards selfadministration, as well as enable more physicians to consider self-administration practices in AATD, in the right patient. In addition, there needs to be greater access to education and training resources to support both HCPs and patients during self-administration practices.

\section{Acknowledgment}

Medical writing support was provided by Hannah Scotney $\mathrm{PhD}$ and Dan Wright PhD of OPEN Health.

\section{Disclosure}

RA Sandhaus has received honoraria, research funding, and/or travel reimbursement from CSL Behring, Grifols, Vertex, AstraZeneca, Takeda, Dicerna, Arrowhead, Inhibrx and the US National Institutes of Health. AM Turner has received grant funding and/or honoraria from CSL Behring, Grifols and Vertex within the last 5 years. $\mathrm{M}$ Sucena has received consulting fees for lectures and participation in advisory boards from Bial, Boehringer Ingelheim, CSL Behring, Grifols and Novartis. FJF Herth reports personal fees from CSL, during the conduct of the study. T Greulich reports personal fees from CSL-Behring, grants from Grifols, outside the submitted work. The authors report no other conflicts of interest in this work.

\section{References}

1. Stoller JK, Aboussouan LS. A review of $\alpha 1$-antitrypsin deficiency. Am J Respir Crit Care Med. 2012;185:246-259.

2. Sharafkhaneh A, Hanania NA, Kim V. Pathogenesis of emphysema: from the bench to the bedside. Proc Am Thorac Soc. 2008;5 (4):475-477. doi:10.1513/pats.200708-126ET

3. Chapman KR, Chorostowska-Wynimko J, Koczulla AR, et al. Alpha 1 antitrypsin to treat lung disease in alpha 1 antitrypsin deficiency: recent developments and clinical implications. Int J Chron Obstruct Pulmon Dis. 2018;13:419-432. doi:10.2147/COPD.S149429

4. Blanco I, Fernández E, Bustillo EF. Alpha-1-antitrypsin PI phenotypes $\mathrm{S}$ and $\mathrm{Z}$ in Europe: an analysis of the published surveys. Clin Genet. 2001;60(1):31-41. doi:10.1034/j.1399-0004.2001.600105.x

5. Brantly ML, Wittes JT, Vogelmeier CF, et al. Use of a highly purified $\alpha 1$-antitrypsin standard to establish ranges for the common normal and deficient a1-antitrypsin phenotypes. Chest. 1991;100(3):703-708. doi:10.1378/chest.100.3.703

6. de Serres FJ. Worldwide racial and ethnic distribution of $\alpha_{1}$-antitrypsin deficiency: summary of an analysis of published genetic epidemiologic surveys. Chest. 2002;122(5):1818-1829. doi:10.1378/chest.122.5.1818

7. Gadek JE, Klein HG, Holland PV, et al. Replacement therapy of alpha 1-antitrypsin deficiency. Reversal of protease-antiprotease imbalance within the alveolar structures of PiZ subjects. J Clin Invest. 1981;68 (5):1158-1165. doi:10.1172/JCI110360

8. Respreeza summary of product characteristics; 2015. Available from: https://www.ema.europa.eu/en/documents/product-information/respreezaepar-product-information_en.pdf. Accessed October, 2021.
9. AATD-Registry. Survival and FEV1 decline in individuals with severe deficiency of alpha1-antitrypsin. Am J Respir Crit Care Med. 1998;158:49-59. doi:10.1164/ajrccm.158.1.9712017

10. Chapman KR, Burdon JGW, Piitulainen E, et al. Intravenous augmentation treatment and lung density in severe $\alpha 1$ antitrypsin deficiency (RAPID): a randomised, double-blind, placebo-controlled trial. Lancet. 2015;386(9991):360-368. doi:10.1016/S0140-6736(15)60860-1

11. Lieberman J. Augmentation therapy reduces frequency of lung infections in antitrypsin deficiency: a new hypothesis with supporting data. Chest. 2000;118(5):1480-1485. doi:10.1378/chest.118.5.1480

12. Seersholm N, Wencker M, Banik N, et al. Does $\alpha_{1}$-antitrypsin augmentation therapy slow the annual decline in $\mathrm{FEV}_{1}$ in patients with severe hereditary $\alpha_{1}$-antitrypsin deficiency? Wissenschaftliche Arbeitsgemeinschaft zur Therapie von Lungenerkrankungen (WATL) alpha1-AT study group. Eur Respir J. 1997;10(10):2260-2263. doi:10.1183/09031936.97.10102260

13. Rahaghi FF, Monk R, Ramakrishnan V, et al. Alpha-1 antitrypsin augmentation therapy improves survival in severely deficient patients with predicted FEV1 between $10 \%$ and $60 \%$ : a retrospective analysis of the NHLBI alpha-1 antitrypsin deficiency registry. Int $J$ COPD. 2020;15:3193. doi:10.2147/COPD.S263725

14. Horváth I, Canotilho M, Chlumský J, et al. Diagnosis and management of $\alpha 1$-antitrypsin deficiency in Europe: an expert survey. ERJ Open Res. 2019;5(1):00171-2018. doi:10.1183/23120541.00171-2018

15. Sandhaus RA, Strange C, Zanichelli A, et al. Improving the lives of patients with alpha-1 antitrypsin deficiency. Int $J$ Chron Obstruct Pulmon Dis. 2020;15:3313-3322. doi:10.2147/COPD.S276773

16. Epping-Jordan J, Pruitt SD, Bengoa R, Wagner EH. Improving the quality of health care for chronic conditions. BMJ Qual Saf. 2004;13:299-305. doi:10.1136/qshc.2004.010744

17. Gibson PG, Powell H, Wilson A, et al. Self-management education and regular practitioner review for adults with asthma. Cochrane Database Syst Rev. 2003;(1):CD001117. doi:10.1002/14651858.CD001117

18. Monninkhof E, van der Valk PP, van der Palen JJ, et al. Self-management education for chronic obstructive pulmonary disease. Cochrane Database Syst Rev. 2003;(1):CD002990.doi:10.1002/14651858. CD002990

19. Bartholomew LK, Czyzewski DI, Parcel GS, et al. Self-management of cystic fibrosis: short-term outcomes of the cystic fibrosis family education program. Health Educ Behav. 1997;24(5):652-666. doi:10.1177/109019819702400511

20. Khair K, Meerabeau L, Gibson F. Self-management and skills acquisition in boys with haemophilia. Health Expect. 2015;18:1105-1113. doi:10.1111/hex.12083

21. Wencker M, Fuhrmann B, Konietzko N, et al. Longitudinal follow-up of patients with alpha(1)-protease inhibitor deficiency before and during therapy with IV alpha(1)-protease inhibitor. Chest. 2001;119 (3):737-744. doi:10.1378/chest.119.3.737

22. Ficker J, Chapman KR, Turner A, et al. Alpha-1 antitrypsin (A1-PI) treatment slows emphysema progression independent of baseline FEV1. Eur Respir Soc. 2017;50(suppl 61):OA3416.

23. McElvaney NG, Burdon J, Holmes M, et al. Long-term efficacy and safety of $\alpha 1$ proteinase inhibitor treatment for emphysema caused by severe $\alpha 1$ antitrypsin deficiency: an open-label extension trial (RAPID-OLE). Lancet Respir Med. 2017;5(1):51-60. doi:10.1016/ S2213-2600(16)30430-1

24. Administration FFaD. Chronic obstructive pulmonary disease: use of the St. George's respiratory questionnaire as a PRO assessment tool. Guidance for Industry; 2018. Available from: https://www.fda.gov/ regulatory-information/search-fda-guidance-documents/chronicobstructive-pulmonary-disease-use-st-georges-respiratoryquestionnaire-pro-assessment-tool. Accessed October, 2021.

25. Stockley RA, Edgar RG, Starkey S, et al. Health status decline in $\alpha-1$ antitrypsin deficiency: a feasible outcome for disease modifying therapies? Respir Res. 2018;19(1):137. doi:10.1186/s12931-018-0844-6 
26. Ellis P, Holm K, Choate R, et al. Comparison of outcomes in augmentation naïve and augmented patients with alpha-1 antitrypsin deficiency related lung disease. Eur Respir J. 2019;54:PA3383.

27. Sandhaus R, Ellis P, Holm K, et al. Augmentation therapy for alpha- 1 antitrypsin deficiency: improved survival and quality of life compared to matched augmentation naive controls followed for up to 15 years. A92 medical and interventional management of obstructive lung disease. Am J Respir Crit Care Med. 2020;201:A2486.

28. Chorostowska-Wynimko J, Barrecheguren M, Ferrarotti I, et al. New patient-centric approaches to the management of alpha-1 antitrypsin deficiency. Int J COPD. 2020;15:345-355. doi:10.2147/COPD.S234646

29. Wilke A, Grohé C. Prospective evaluation of clinical parameters of AAT patients with i. v. prolastin therapy in a homecare setting. Pneumologie. 2013;67:545-550.

30. Annunziata A, Lanza M, Coppola A, et al. Alpha-1 antitrypsin deficiency: home therapy. Front Pharmacol. 2021;12:575402. doi:10.3389/fphar.2021.575402

31. Symons C, Rossi O, Magerl M, et al. Practical approach to self-administration of intravenous $\mathrm{C} 1-\mathrm{INH}$ concentrate: a nursing perspective. Int Arch Allergy Immunol. 2013;161(Suppl s1):17-20. doi:10.1159/000351236

32. Craig TJ. Recent advances in hereditary angioedema self-administration treatment: summary of an international hereditary angioedema expert meeting. Int Arch Allergy Immunol. 2013;161 (s1):26. doi:10.1159/000351241

33. Tonna A, Anthony G, Tonna I, et al. Home self-administration of intravenous antibiotics as part of an outpatient parenteral antibiotic therapy service: a qualitative study of the perspectives of patients who do not self-administer. BMJ Open. 2019;9(1):e027475. doi:10.1136/bmjopen-2018-027475

34. Boysen HB, Bouillet L, Aygören-Pürsün E. Challenges of C1-inhibitor concentrate self-administration. Int Arch Allergy Immunol. 2013;161(Suppl 1):21-25. doi:10.1159/000351238

35. Bygum A, Andersen KE, Mikkelsen CS. Self-administration of intravenous $\mathrm{C} 1$-inhibitor therapy for hereditary angioedema and associated quality of life benefits. Eur $J$ Dermatol. 2009;19(2):147-151. doi:10.1684/ejd.2008.0603

36. Stiver HG, Trosky SK, Cote DD, Oruck JL. Self-administration of intravenous antibiotics: an efficient, cost-effective home care program. Can Med Assoc J. 1982;127:207-211.

37. Boyd BS. Alpha 1 antitrypsin therapy: a satisfaction survey of individuals self-administering. A46 topics in alpha-1 antitrypsin deficiency. Am J Respir Crit Care Med. 2018;197:A1758.

38. Zanichelli A, Azin GM, Cristina F, et al. Safety, effectiveness, and impact on quality of life of self-administration with plasma-derived nanofiltered $\mathrm{C} 1$ inhibitor $\left(\right.$ Berinert $^{(\mathbb{})}$ ) in patients with hereditary angioedema: the SABHA study. Orphanet J Rare Dis. 2018;13 (1):1-8. doi:10.1186/s13023-018-0797-3

39. Longhurst HJ, Farkas H, Craig T, et al. HAE international home therapy consensus document. Allergy Asthma Clin Immunol. 2010;6 (1):1-7. doi:10.1186/1710-1492-6-22

40. Ochs HD, Gupta S, Kiessling P, et al. Safety and efficacy of self-administered subcutaneous immunoglobulin in patients with primary immunodeficiency diseases. J Clin Immunol. 2006;26 (3):265-273. doi:10.1007/s10875-006-9021-7

41. Kayley J, Berendt AR, Snelling MJM, et al. Safe intravenous antibiotic therapy at home: experience of a UK based programme. J Antimicrob Chemother. 1996;37(5):1023-1029. doi:10.1093/jac/37.5.1023

42. Wencker M, Banik N, Buhl R, et al. Long-term treatment of alpha1-antitrypsin deficiency-related pulmonary emphysema with human alpha1-antitrypsin. Wissenschaftliche Arbeitsgemeinschaft zur Therapie von Lungenerkrankungen (WATL)-alpha1-AT-study group. Eur Respir J. 1998;11:428-433. doi:10.1183/09031936.98.11020428

43. Vilasuso M, Barnett N. Self-medication - take it or leave it. Pharmaceutical J. 2007;278:72
44. Patient Self Administration of Intravenous (IV) Antibiotics at Home. West Suffolk NHS Foundation Trust Policy. Document Ref. No: PP (19)319; 2019.

45. Self-management of diabetes in hospital. NHS Diabetes; 2012. Available from: https:/www.diabetes.org.uk/professionals/position-statementsreports/specialist-care-for-children-and-adults-and-complications/selfmanagement-of-diabetes-in-hospital. Accessed October, 2021.

46. Frid AH, Kreugel G, Grassi G, et al. New insulin delivery recommendations. Mayo Clin Proc. 2016;91:1231-1255.

47. Sandhaus RA, Turino G, Brantly ML, et al. The diagnosis and management of alpha-1 antitrypsin deficiency in the adult. Chronic Obstr Pulm Dis. 2016;3:668-682.

48. American Thoracic Society/European Respiratory Society Statement. European respiratory society statement: standards for the diagnosis and management of individuals with alpha-1 antitrypsin deficiency. Am J Respir Crit Care Med. 2003;168:818-900. doi:10.1164/ rccm.168.7.818

49. Gaeckle NT, Stephenson L, Reilkoff RA. Alpha-1 antitrypsin deficiency and pregnancy. COPD. 2020;17(3):326-332. doi:10.1080/ 15412555.2020.1754778

50. Prolastin summary of product characteristics 2021. Available from: https://www.hpra.ie/img/uploaded/swedocuments/Licence_PA1405002-001_23062021102832.pdf. Accessed October, 2021.

51. Aralast summary of product characteristics; 2018. Available from: https://myhealthbox.eu/en/vi6ew/2419858/c651c6b14ae f987a406b2fb4ce168fbf/leaflet. Accessed October, 2021.

52. Glassia highlights of prescribing information. Available from: https:// www.fda.gov/media/78773/download. Accessed October, 2021.

53. Rizk C, Karsh J, Santucci S, et al. Self-administration of intravenous C1 esterase inhibitor in hereditary angioedema. CMAJ. 2013;185 (9):791-792. doi:10.1503/cmaj.121364

54. Guidelines for the management of Hemophilia; 2012. Available from: www.wfh.org. Accessed October, 2021

55. Administration ENGfI. SCIG Self-Administration at Home - In Adults. 2019. Immunodeficiences INGf, ed. 64-76.

56. Guideline on good pharmacovigilance practices (GVP); 2012. Available from: https://www.ema.europa.eu/en/documents/scienti fic-guideline/draft-guideline-good-pharmacovigilance-practicesmodule-vi-management-reporting-adverse-reactions_en.pdf. Accessed October, 2021.

57. European Medicines Agency. How to report a side effect; 2020. Available from: http://www.adrreports.eu/docs/ADR_reporting FINAL_EN.pdf. Accessed October, 2021.

58. O'Brien ME, Fee L, Browne N, et al. Activation of complement component 3 is associated with airways disease and pulmonary emphysema in alpha-1 antitrypsin deficiency. Thorax. 2020;75 (4):321-330. doi:10.1136/thoraxjnl-2019-214076

59. McElvaney OJ, Carroll TP, Franciosi AN, et al. Consequences of abrupt cessation of alpha 1-antitrypsin replacement therapy. $N$ Engl J Med. 2020;382(15):1478-1480. doi:10.1056/NEJMc191 5484

60. Fischer H-P, Ortiz-Pallardó ME, Ko Y, et al. Chronic liver disease in heterozygous $\alpha 1$-antitrypsin deficiency PiZ. J Hepatol. 2000;33 (6):883-892. doi:10.1016/S0168-8278(00)80119-1

61. Hill AT, Campbell E, Bayley D, et al. Evidence for excessive bronchial inflammation during an acute exacerbation of chronic obstructive pulmonary disease in patients with $\alpha 1$-antitrypsin deficiency (PiZ). Am J Respir Crit Care Med. 1999;160(6):1968-1975. doi:10. 1164/ajrccm.160.6.9904097

62. Yang C, Chapman KR, Wong A, et al. $\alpha 1$-antitrypsin deficiency and the risk of COVID-19: an urgent call to action. Lancet Respir Med. 2021;9(4):337-339. doi:10.1016/S2213-2600(21)00018-7

63. Bai X, Hippensteel J, Leavitt A, et al. Hypothesis: alpha-1-antitrypsin is a promising treatment option for COVID-19. Med Hypotheses. 2021;146:110394. doi:10.1016/j.mehy.2020.110394 
64. Azouz NP, Klingler AM, Callahan V, et al. Alpha 1 antitrypsin is an inhibitor of the SARS-CoV-2-priming protease TMPRSS2. Pathog Immun. 2021;6:55

65. Tanash HA, Ekström M, Wagner P, et al. Cause-specific mortality in individuals with severe alpha 1-antitrypsin deficiency in comparison with the general population in Sweden. Int J Chron Obstruct Pulmon Dis. 2016;11:1663-1669. doi:10.2147/COPD.S109173

66. Zhang $\mathrm{X}$, Yang $\mathrm{X}$, Jiao $\mathrm{H}$, et al. Coagulopathy in patients with COVID-19: a systematic review and meta-analysis. Aging. 2020;12 (24):24535-24551. doi:10.18632/aging.104138

67. McElvaney OJ, McEvoy NL, McElvaney OF, et al. Characterization of the inflammatory response to severe COVID-19 illness. Am J Respir Crit Care Med. 2020;202:812-821. doi:10.1164/rccm.202005-1583OC

68. Miravitlles M, Chorostowska-Wynimko J, Ferrarotti I, et al. The European Alpha-1 Research Collaboration (EARCO): a new ERS clinical research collaboration to promote research in alpha-1 antitrypsin deficiency. Eur Respir J. 2019;53(2):1900138. doi:10.1183/ 13993003.00138-2019

69. AlphaNet. Available from: https://www.alphanet.org/. Accessed October, 2021.

70. Zádori N, Váncsa S, Farkas N, et al. The negative impact of comorbidities on the disease course of COVID-19. Intensive Care Med. 2020;46(9):1784-1786. doi:10.1007/s00134-020-06161-9

71. Alqahtani JS, Oyelade T, Aldhahir AM, et al. Prevalence, severity and mortality associated with COPD and smoking in patients with COVID-19: a rapid systematic review and meta-analysis. PLoS One. 2020;15(5):e0233147. doi:10.1371/journal.pone.0233147
72. Campos MA, Kueppers F, Stocks JM, et al. Safety and pharmacokinetics of $120 \mathrm{mg} / \mathrm{kg}$ versus $60 \mathrm{mg} / \mathrm{kg}$ weekly intravenous infusions of alpha-1 proteinase inhibitor in alpha-1 antitrypsin deficiency: a multicenter, randomized, double-blind, crossover study (SPARK). COPD. 2013;10(6):687-695. doi:10.3109/15412555.2013.800852

73. Greulich T, Chlumsky J, Wencker M, et al. Safety of biweekly $\alpha_{1}$ antitrypsin treatment in the RAPID programme. Eur Respir J. 2018;52(5):1800897. doi:10.1183/13993003.00897-2018

74. Ritzmann F, Chitirala P, Krüger N, et al. Therapeutic application of alpha-1-antitrypsin in COVID-19. Am J Respir Crit Care Med. 2021. doi:10.1164/rccm.202104-0833LE

75. Clinical trials.gov. NCT04385836. Available from: https://clinical trials.gov/ct2/show/NCT04385836?term=COVID-19+antitrypsin +therapy\&draw $=2 \&$ rank $=6$. Accessed October, 2021.

76. EU Clinical Trial Register. 2020-001391-15. Available from: https:// www.clinicaltrialsregister.eu/ctr-search/trial/2020-001391-15/IE. Accessed October, 2021.

77. Clinical trials.gov. NCT04495101. Available from: Available from: https://clinicaltrials.gov/ct2/show/NCT04495101?term= NCT04495101\&draw=2\&rank=1. Accessed October, 2021.

78. Clinical trials.gov. NCT04547140. Available from: https://clinical trials.gov/ct2/show/NCT04547140?term=Alpha+1+in+COVID$19 \&$ draw $=2 \&$ rank=1. Accessed October, 2021.

International Journal of Chronic Obstructive Pulmonary Disease

\section{Publish your work in this journal}

The International Journal of COPD is an international, peer-reviewed journal of therapeutics and pharmacology focusing on concise rapid reporting of clinical studies and reviews in COPD. Special focus is given to the pathophysiological processes underlying the disease, intervention programs, patient focused education, and self management protocols. This journal is indexed on PubMed Central, MedLine and CAS. The manuscript management system is completely online and includes a very quick and fair peer-review system, which is all easy to use. Visit http://www.dovepress.com/testimonials.php to read real quotes from published authors. 